Original Article

\title{
Extent of awareness regarding periodontal disease in diabetic patients among medical interns
}

\author{
Roshni Jaiswal ${ }^{1}$, Nina Shenoy ${ }^{2} \&$ Biju Thomas $^{3}$ \\ ${ }^{1}$ Post Graduate, ${ }^{2}$ Professor, ${ }^{3}$ Professor \& HOD, Department of Periodontics, \\ A.B. Shetty M emorial Institute of Dental Sciences, Nitte University, M angalore, Karnataka, India. \\ Correspondence \\ Roshni Jaiswal \\ Post Graduate, Department of Periodontics, A. B. Shetty Memorial Institute of Dental Sciences, \\ Nitte University, M angalore - 575 018, Karnataka, India. \\ Mobile : +919886800925 E-mail : roshnijaiswal4@gmail.com
}

\begin{abstract}
Background: Diabetes mellitus is a metabolic disorder characterized by hyperglycemia due to defective secretion or activity of insulin. Prevalence of diabetes mellitus has tripled since 1970, hence it is a significant finding for dental professionals, as evidence from clinical research showing a strong relationship between diabetes and periodontal disease is mounting. In fact, periodontitis is often referred to as the sixth complication of diabetes.
\end{abstract}

Objective: To assess the extent of awareness of periodontal disease in diabetic patients, among medical interns.

Methods: A cross sectional survey containing 21 questions was answered by 150 medical interns from M angalore, Karntaka.

Conclusion: The results of this survey indicate that medical interns have thorough knowledge about diabetes and its complications; however, their awareness about periodontal disease in diabetic patients is limited thus further emphasis should be given to the dissemination of knowledge about the inter-relationship of diabetes and periodontal health.

Keywords: Diabetes, Periodontitis, M edical Interns.

\section{Introduction}

The Expert Committee of the American Diabetes Association in 2003 defined diabetes mellitus as a group of chronic metabolic diseases characterized by hyperglycemia resulting from defects in insulin secretion, insulin action, or both. ${ }^{(1)}$ It leads to complications such as microangiopathy, retinopathy, nephropathy, microvascular disease and delayed wound healing. ${ }^{(2)}$

Individuals with poorly controlled diabetes have also been found to be more susceptible to oral infections including periodontitis being its $6^{\text {th }}$ complication). ${ }^{(3)}$

\begin{tabular}{|c|}
\hline Access this article online \\
\hline Quick Response Code \\
\hline
\end{tabular}

It has been reported that subjects with diabetes have a greater prevalence and severity of periodontal disease compared with subjects without diabetes in all age groups. $^{(4)}$
In these subjects, diabetes also increases the progression of bone loss and attachment loss over time. ${ }^{(5)}$ There have been various studies which have demonstrated a bidirectional relationship between periodontal disease and diabetes. ${ }^{(6)(7)(8)}$

The relationship between oral diseases and type 2 diabetes has become a recent focus of attention

among health care professionals because of substantial evidence supporting the role of diabetes

and poor glycemic control as important risk factors for periodontal disease. ${ }^{(9)}$ Furthermore, it appears that periodontal diseases can contribute to poorer glycemic control in people with diabetes and that treating periodontal infections could have a beneficial effect on glycemic control in either type 1 or type 2 diabetes. ${ }^{(10)}$

Additionally, there is growing evidence that clinical practitioners should incorporate education concerning the risk of periodontal disease into the management regimens 
of their patients with diabetes. It is also important to communicate with physicians and others involved in diabetes care about the importance of referring patients with diabetes for thorough oral health evaluations. ${ }^{(11)}$.Thus, medical practitioners should also possess basic dental knowledge to uncover signs and symptoms of dental diseases from patients, to provide appropriate treatment or advice to these patients and to act as public health educators ${ }^{(12)}$.

Hence the present study seeks to assess the knowledge of periodontal disease and awareness of its inter-relationship with diabetes among medical interns, as they can also play a pivotal role in preventing the further progression of periodontal disease in such patients.

\section{Aims \& Objectives}

- To assess the knowledge of periodontal disease among medical interns.

- To assess their awareness of periodontal disease in diabetic patients.

\section{Material \& Methods}

A cross sectional questionnaire survey containing 21 questions was used to assess the extent of awareness of periodontal disease in diabetic patients among medical interns. A non-probability sampling, or convenience sampling method was used to chose participants. Convenient sample size of 150 medical interns from Mangalore, Karnataka were chosen. Ethical clearance certificate was obtained from the institution for the same.

\section{Statistical Analysis}

Data obtained was analyzed using the SPSS (Statistical

1. What is Periodontitis?

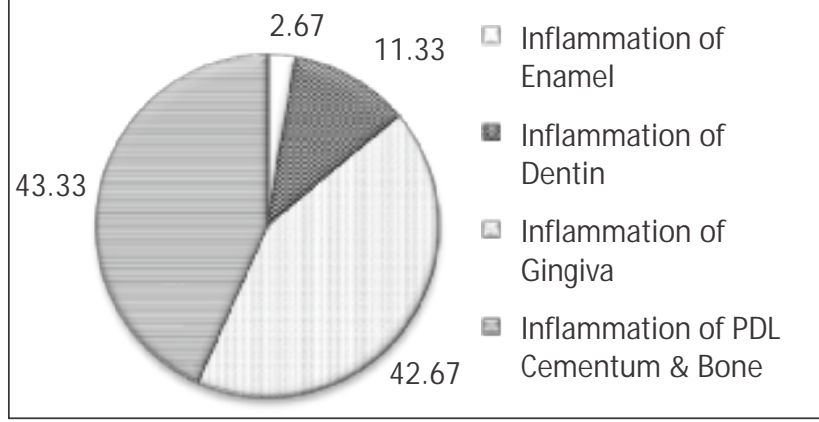

package for social sciences) version16.

\section{Results}

Following pie charts depict 14 most relevant questions from the questionnaire survey.

Table1: Depicting pie diagram with response in (\%) Q1-8

Table 2: Depicting Pie diagram with response in (\%) Q9-14

\section{Discussion}

As per the results depicted in pie charts, this study indicates that more than half $(>50 \%)$ of medical interns are thorough with the knowledge of diabetes in general and its systemic complications.

A majority of respondents i.e. $68 \%$ were not aware if diabetic patients develop periodontal disease (Q6). Also around $50 \%$ of medical interns could not specify periodontal manifestations diabetic patients can present with. (Q8\&Q9)

Around $70 \%$ of the interns felt that they have limited knowledge about periodontal disease and its association with systemic disease like diabetes (Q13), though 30\% strongly agree to the idea that discussing or evaluating periodontal status should be an important part of their examination.

As per this study its evident that medical interns have good knowledge about diabetes and its complications, though there is a need to emphasize the importance of oral health care in patients suffering from diabetes and also understand the bi-directional relationship between diabetes and periodontal disease so that they can also play a significant role in preventing its further progression by timely referral to the dentist / periodontist.

2. What are the clinical manifestations in Periodontitis?

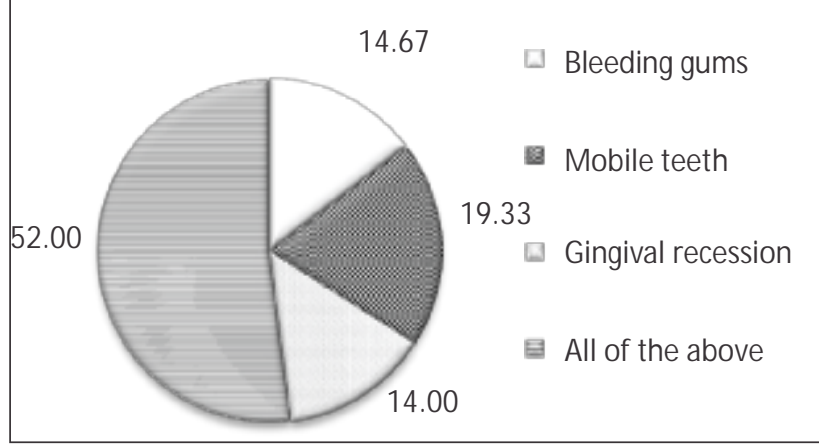


3. What is the range of normal fasting blood glucose level?

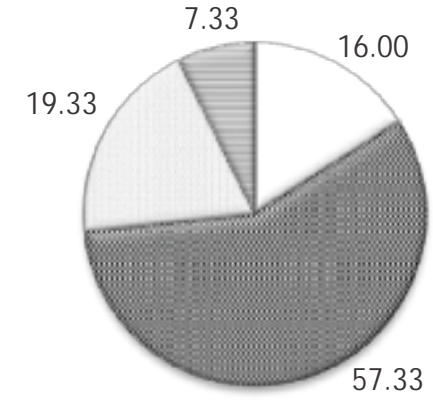

$\square 50-69 \mathrm{mg} / \mathrm{dl}$

70-99mg/dl

$\square 100-125 \mathrm{mg} / \mathrm{dl}$

目 $126 \mathrm{mg} / \mathrm{dl}$ or higher on separate tests

5. Periodontitis is the mellitus.

complication of diabetes

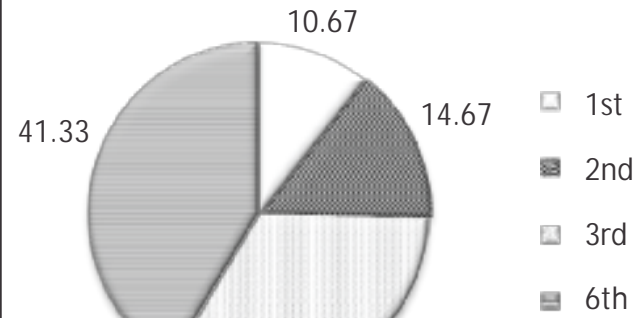

33.33

7. Do you ask your patients if they have ever been diagnosed with a periodontal disease?

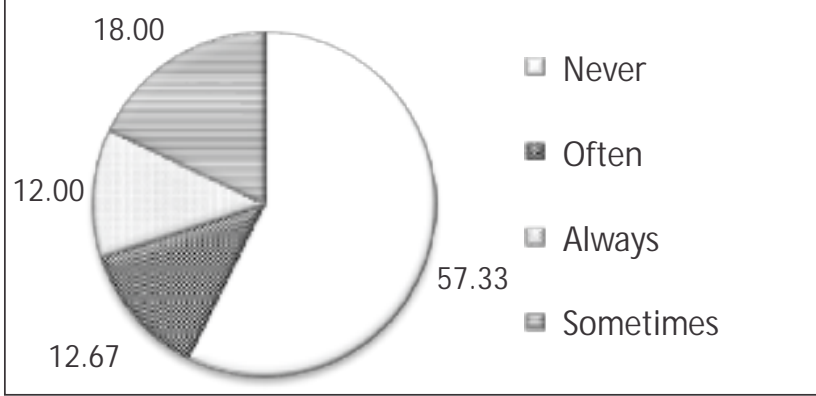

9. Which is the most common oral micro vascular complications observed in diabetes mellitus?

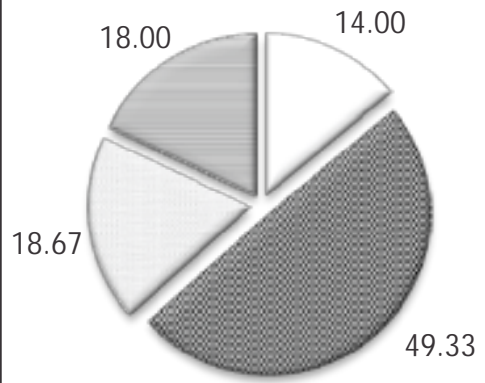

$\square$ Xerostomia

angivitis

$\square$ Leukoplakia

目 Gingival Enlargement
4. As per ADA fasting blood glucose test level which indicates diabetes is?

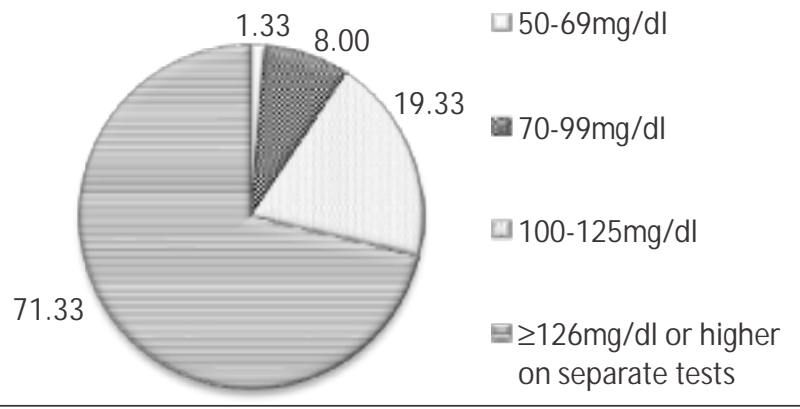

6. Are you aware that diabetics are prone to develop periodontal disease?

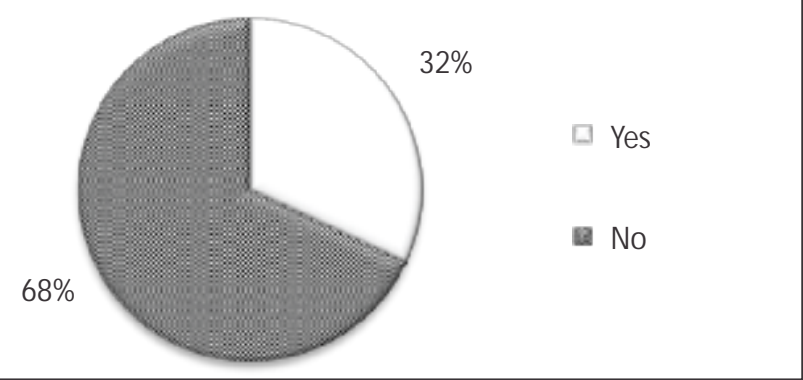

8. Which is the most common periodontal manifestation seen in an uncontrolled diabetic patient?

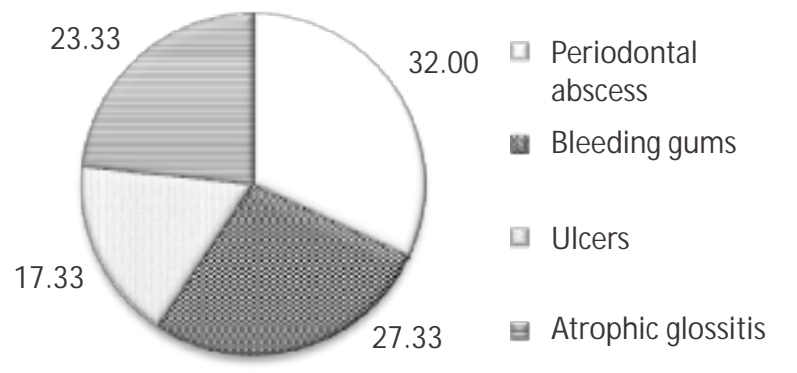

10. Rapid destruction of periodontal structures in poorly controlled diabetic is due to?

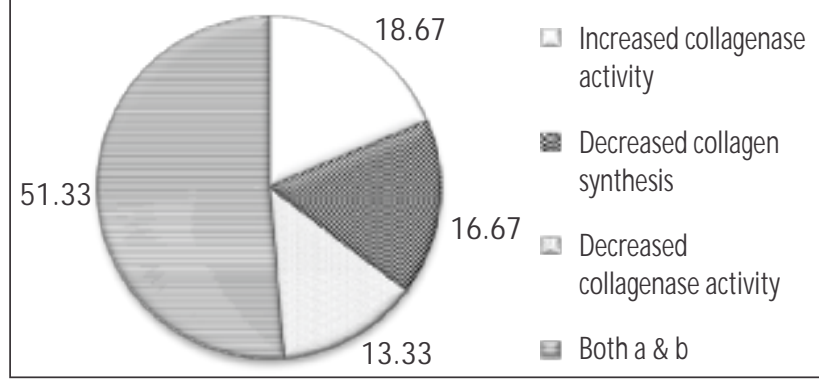


11. Do you refer your patient for evaluation/care?

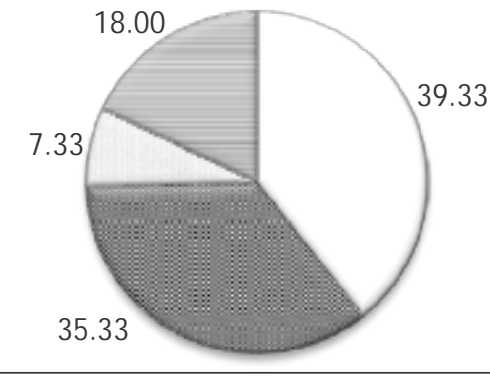

$\square$ Never

Sometimes

$\square$ Often

目 Always

13. How would you rate your knowledge about periodontal disease and its association with systemic disease?

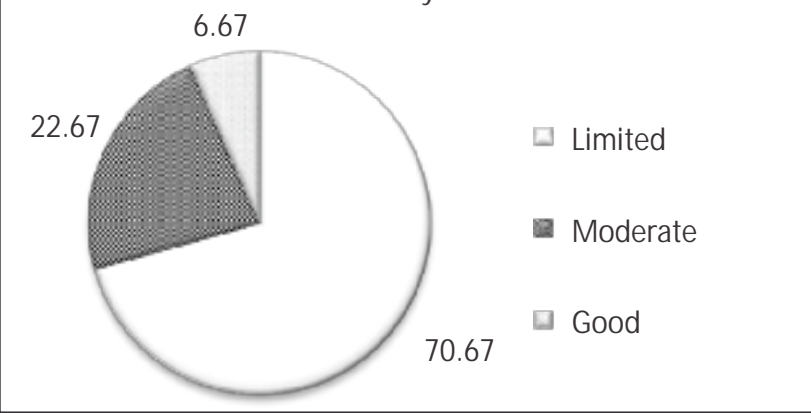

\section{Conclusion}

As per the results of this study it can be concluded that although medical interns have thorough knowledge about diabetes, their knowledge about periodontal disease is finite. Also, they are

unaware of the periodontal manifestations in such patients. Furthermore, they have limited knowledge about the inter-relationship of the diabetes and periodontal disease.

Medical interns are budding physicians of the future who have an opportunity to encourage oral health and thus can make a significant difference because of their access to families as a family physician. It is also incumbent upon medical practitioners to keep their knowledge updated

\section{References}

1. American Diabetes Association. Economic (2003).Costs of Diabetes in the U.S. in 2002. Diabetes Care, 26, 917-932.

2. Kinane, D.F. \&Chestnutt, I.G. 1997. Relationship of diabetes to periodontitis. Curr. Opin. Periodontol. 4: 29-34

3. Loe, H. 1993. Periodontal disease: The sixth complication of diabetes mellitus. Diabetes Care16(suppl 1): 329-334.

4. Emrich, L.J., Shlossman, M. \&Genco, R.J . 1991. Periodontal disease in non-insulin-dependent diabetes mellitus. J. Periodontol. 62: 123-131.

5. Taylor, G.W., Burt, B.A., Becker, M.P., Genco, R.J., Shlossman, M., Knowler, W.C. \&Pettitt, D.J. 1998. Glycemic control \&alv bone loss
12. What do you advise to diabetic patients who have or are at riskfor periodontal disease?

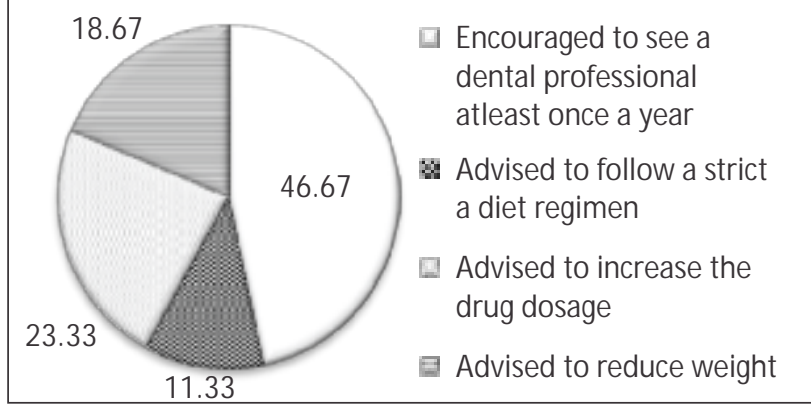

14. Discussing / evaluating periodontal status is peripheral to myrole asa physician

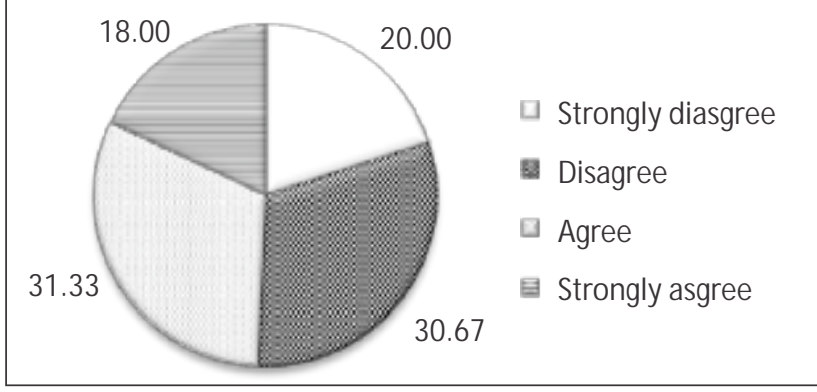

with time and get actively involved in oral health, as oral cavity is a mirror of systemic conditions.

\section{Recommendations}

- To encourage newly graduated medical practitioners to examine the oral cavity (including teeth and gums) during their general examination for patients. ${ }^{(14)}$

- To promote the setting up of associate clinics, which will include both medical practitioners and dental practitioners for the benefit of providing medical and dental services under one roof.

To conduct continuing education programmes to improve their knowledge, attitude and awareness about various dental diseases.

progression in type 2 diabetes. Ann. Periodontol. 3: 30-39.

6 .Matthews, D.C. (2002). The relationship between diabetes and periodontal disease. Journal of the Canadian Dental Association, 68, 161-164.

7. Ryan, M.E., Carnu, O., \&Kamer, A. (2003).The influence of diabetes on the periodontal tissues.J ournal of the American Dental Association, $134,34 \mathrm{~S}-40 \mathrm{~S}$

8. Nishimura, F., Iwamoto, Y., Mineshiba, J.,Shimizu, A., Soga, Y., \&M uayama, Y. (2003).Periodontal disease and diabetes mellitus: the role oftumor necrosis factor-a in a 2-way relationship.Journal of 
Periodontology, 74, 97-102.

9. Taylor, G.W., Manz, M.C., \&Borgnakke,W.S. (2004, M arch). Diabetes, periodontal diseases, dental caries, and tooth loss: a review of theliterature. Compendium of Continuing Education in Dentistry, 179190.

10. Jin, L.J., Chiu, G.K.C., \&Corbet, E.F.(2003). Are periodontal diseases risk factors forcertain systemic disorders-what matters to medical practitioners? Hong Kong M edical Journal, 9, 31-37.

11. Robertson, C. Drexler, A.J., \&Vernillo, A.T. (2003). Update on diabetes diagnosis and management. Journal of the American Dental
Association, 134, 16S-23S.

12. Naidu RS, Juman S, Rafeek RN, et al.Oral and dental conditions presenting to medical practitioners in Trinidad and Tobago. International Dental Journal2008; 5:194-98.

13. Al-Hussaini R, Al-Kandari M, Hamadi T.Dental knowledge, attitudes and behavior among students at the Kuwait university health sciences centre. Medical Principles and Practice 2003; 12:260-65.

14. Srinidhi, Navin Anand Ingle, PreethaElizebethChaly, Chandrasekhara Reddy. Dental awareness and attitudes among medical practitioners in Chennai.J Oral Health Comm Dent 2011; 5(2)73-78 